\title{
Understanding Suicide Attempts Among Gay Men From Their Self-perceived Causes
}

\author{
Jen Wang, MPH, PhD, *† Martin Plöderl, PhD, $\$$ Michael Häusermann, LSW, \\ and Mitchell G. Weiss, MD, PhD $+\|$
}

\begin{abstract}
Gay men are at higher risk of suicidality. This paper describes the causes of suicide attempts as perceived by the men themselves and analyzes their impact on severity and recidivism. Mental health surveys conducted among gay men in Geneva, Switzerland, from two probability-based time-space samples in 2007 and 2011, were merged to yield a combined sample $N=762$. Suicide ideation, plans, and attempts were assessed, and respondents who had ever attempted suicide answered open questions about perceived causes which were coded and categorized for analysis within the framework of cultural epidemiology. In all, $16.7 \%$ of the respondents reported a suicide attempt in their lifetime (59.5\% of them with multiple attempts). At their latest attempt, over two thirds asserted intent to die, and half required medical assistance. There was a wide variety of perceived causes, with most individuals reporting multiple causes and many of the most common causes cited at both the first and most recent subsequent attempts. Social/inter-personal problems constitute the most prominent category. Problems with love/relationship and accepting one's homosexuality figure consistently among the top three causes. Whereas the former tend to be associated with weaker intent to die, the latter are associated with the strongest intent to die and reported at multiple attempts. Problems with family are among the most common perceived causes at first attempt but not at the most recent subsequent attempt. Nevertheless, they tend to be related to the strongest intent to die and the greatest medical severity of all the perceived causes. Ten percent of men attempting suicide cited depression as a cause. Although it tended to be associated with weaker intent to die, depression was most likely to be reported at multiple attempts. Respondent-driven assessment yielded both common and idiosyncratic causes of suicide and their distinct effects. Some of these perceived causes are not prominent in the current literature, yet they have important implications for understanding risk and preventing suicide among gay men.
\end{abstract}

Key Words: Suicide, recidivism, cultural epidemiology, life events, homosexuality

( Nerv Ment Dis 2015;203: 499-506)

So everal reviews and meta-analyses have summarized the growing body of evidence pointing to higher risk of suicidality among sexual minorities generally and gay men in particular (King et al., 2008; Plöderl et al., 2006, 2013). In accordance with the international literature, Swiss findings have shown that a majority of gay/bisexual men reported one or more of the main forms of suicidality-i.e., suicidal ideation, suicide plans, and suicide attempts - in their lifetime, with every sixth man reporting an attempt to end his life (Wang et al., 2012). In fact, the proportions of gay men thinking about or actually attempting suicide in the past 12 months (Wang et al., 2012, 2014a) correspond

*Institute for Social and Preventive Medicine, University of Zurich, Zurich; †Swiss Tropical and Public Health Institute, Basel, Switzerland; \$Christian Doppler Klinik Salzburg, Salzburg, Austria; §Dialogai, Geneva; and \|University of Basel, Basel, Switzerland.

Send reprint requests to Jen Wang, MPH, PhD, Institute for Social and Preventive

Medicine, Hirschengraben 84, CH-8001 Zurich, Switzerland.

E-mail: jwang@ifspm.uzh.ch.

Copyright (C) 2015 Wolters Kluwer Health, Inc. All rights reserved.

ISSN: 0022-3018/15/20307-0499

DOI: 10.1097/NMD.0000000000000319 to or exceed levels seen among general population or heterosexual men over an entire lifetime (Kjøller and Helweg-Larsen, 2000).

A recent review highlighted mental disorders (including mood, anxiety, and substance use disorders) and individual discrimination (including parental rejection and victimization by violence) as the main factors for the increased risk of suicide attempt among sexual minorities, although neither factor has been shown to explain excess risk entirely (Haas et al., 2011). In mainstream suicide research, both psychiatric and social/familial factors have been shown to be highly relevant for suicide and suicidality (Gvion and Apter, 2012; Nock et al., 2008), particularly among adolescents (Bursztein and Apter, 2008; Cash and Bridge, 2009). It is notable, however, that certain areas of mainstream suicide research - e.g., consideration of biologic factors, psychological factors (e.g., personality traits), and stressful life events - have not been addressed in suicide research among sexual minorities to date.

Though constituting only a sliver of mainstream suicide research (Hjelmeland and Knizek, 2010), some qualitative studies from Europe have underscored the primacy of inter-personal relationship issues in completed suicides (Shiner et al., 2009; Scourfield et al., 2012) and non-fatal suicide attempts involving hospitalization (Valach et al., 2006). For the latter, studies have also highlighted psychological distress and unsolvable problems (Cleary, 2012; Skogman Pavulans et al., 2012). A US psychological autopsy study using qualitative assessment of stressors found that gay men were just as likely as heterosexual men to commit suicide due to relationship break-ups (most commonly reported cause) and financial problems (third most commonly reported cause), but significantly less likely due to job problems (second most commonly reported cause) (Rich et al., 1986). In UK studies among sexual minorities recruited via organizations (Johnson et al., 2007) and among gay men recruited at venues (Hutchison et al., 2003), problems with sexual orientation, depression, relationships, family, and violence were the most common reasons cited by those with a previous suicide attempt.

Despite some overlap, quantitative and qualitative approaches do not necessarily prioritize the same factors. Integrating both quantitative and qualitative methodologies may, therefore, provide a fruitful approach to explain the how and why of suicide (Hjelmeland and Knizek, 2010). Acknowledging the value of combining quantitative and qualitative methods, cultural epidemiological research on locally valid representations of suicide from the respondents' perspective has shown that survivors in both India and Switzerland report inter-personal problems (especially those with romantic partners and family) most commonly as causes or triggers for recent suicide attempts (Parkar et al., 2006; Sauerborn and Banerjee, 2006). Because this approach has not been utilized to date in the study of suicide among sexual minorities, this paper offers additional insights into suicide attempts among gay men, by drawing on features of cultural epidemiology (1) to learn the causes as perceived and expressed by the men themselves and (2) to examine their potential impact on severity and repeat attempts.

\section{METHODS}

The Geneva Gay Men's Health Survey (GGMHS) was repeated in 2007 and 2011 with a focus on mental health, and the methods have been described in detail elsewhere (Wang et al., 2013). 


\section{Samples}

Briefly, the target population consisted of gay-identified men and other men who have sex with men who access meeting pointsboth real and virtual - in Geneva, Switzerland. Each survey employed time-space sampling, a multi-stage randomized sampling scheme developed by the Centers for Disease Control and Prevention (CDC), involving mapping of meeting points, enumeration of visits, and random selection of both venues and participants (MacKellar et al., 1996; Stueve et al., 2001). Men were informed and invited to participate in a general health survey, and consenting respondents were given a unique access code to complete the anonymous survey in French either immediately at laptops provided on-site or later at a time of their own choosing online. In 2007, 276 gay men participated in the survey (response rate $44 \%$ ), whereas in 2011, 486 gay men participated (response rate $38 \%$ ), as the target sample size had been doubled due to changes in study design.

\section{Survey Questions}

Twelve-month and lifetime suicidality were measured using Paykel's items covering suicidal ideation ("Have you ever thought of taking your life, even if you would not really do it?"), suicide plans ("Have you ever reached the point where you seriously considered taking your life or perhaps made plans how you would go about doing it?"), and suicide attempt ("Have you ever made an attempt to take your life?”) (Paykel et al., 1974).

Those respondents who had ever attempted suicide were asked a series of follow-up questions starting with the number of suicide attempts and age at first attempt. Severity was measured by the question "Did you require medical treatment after you tried to kill yourself?" (Bucholz et al., 1994). Intent to die was measured by the question "Did you really want to die?" (absolutely, somewhat, not really, not at all) (Bucholz et al., 1994). We were interested in learning how gay men assessed and expressed the causes precipitating their suicide attempt, so men were asked an open question about the causes for the most recent attempt and, in the case of multiple attempts, for the very first attempt as per the socio-cultural autopsy within the framework of the Explanatory Model Interview Catalog (EMIC) (Parkar et al., 2012; Weiss, 1997).

Depression was assessed by a series of questions recommended by the EUROHIS project on harmonizing indicators for health interview surveys in Europe (Nosikov and Gudex, 2003)-i.e., (1) self-reported history of chronic depression taken from a standardized checklist of chronic conditions modified to yield both 12-month and lifetime prevalences (Eurostat, 2007) and (2) assessment of 12-month major depression by the WHO Composite International Diagnostic Interview Short Form (CIDI-SF) (Kessler et al., 1998). Respondents fulfilling diagnostic criteria for major depression were asked a series of follow-up questions on onset, perceived causes, and help-seeking. The findings for depression are presented in detail elsewhere (Wang et al., 2014b).

\section{Analysis}

The men's responses to the open questions drove the analysis and formulation of a code system. Verbatim responses to the open questions about perceived causes were classified and coded with reference to problem-related experience, meaning, and behavior within the framework of cultural epidemiology (Weiss, 2001). Because most responses were brief, and because quite a few responses contained spelling errors for key terms, they were imported into an Excel file and hand-coded by one researcher in three or more iterations. At each iteration, the codes were compared within and between questions, so that eventually, an overall framework emerged which facilitated identification of key terms and comparison across all open questions for suicide attempt, major depression, and anxiety (simple and social phobias) in both 2007 and 2011.

In all, there were 39 distinct codes for the two questions on perceived causes for the latest and initial suicide attempts in the 2007 and 2011 surveys. To facilitate tabulation and further analysis, all individual codes were grouped into nine over-arching categories which were also harmonized across all conditions and both datasets. A strict distinction was maintained between "disease" and "problem" along the following categories: disease (unspecified), mental disorder, somatic disease, problems (general), mental problems, social/inter-personal problems, lifestyle problems, problems with homosexuality, and "don't know". All codes and categories were reviewed by a second researcher. As there was over-arching consensus, coding by additional researchers was deemed unnecessary.

The findings reported in this paper come from the entire community sample of gay men and, in particular, a subsample of those gay men who attempted suicide in their lifetime. To increase statistical power for the latter, we combined the 2007 and 2011 datasets. Data analysis was performed using IBM SPSS Statistics for Macintosh version 19.0 (Chicago, IL). All nine categories were used for statistical analysis, but from the 39 distinct codes for individual causes, only 13 codes reached a threshold of at least $5 \%$ in any of the columns - all latest attempts, all first attempts, first of multiple attempts, or most recent subsequent attempts - and were imported into SPSS for statistical analysis. Each cause was coded as a separate variable in a binary fashion-i.e., cause present (1) or cause absent (0) — and in calculating odds ratios, the latter always constituted the baseline category, excluded in the tables for greater legibility.

To assess the impact of perceived causes on intent to die and medical severity, odds ratios (OR) and $95 \%$ confidence intervals $(\mathrm{CI})$ were calculated for all latest attempts. To assess the general impact of perceived causes on any repeat attempt, OR and 95\% CI were calculated for all first attempts. To assess the specific impact of perceived causes among repeat attempters, the McNemar test was used to assess series-level agreement (i.e., agreement between first attempts and most recent attempts at the group level), and the kappa statistic was calculated to assess case-level agreement (i.e., agreement between first attempts and most recent subsequent attempts at the individual level) (Parkar et al., 2012). Given cells with small numbers, the exact twosided $p$-value calculated with binomial distribution for the McNemar test is appropriate and reported here, and lower $p$-values indicate lower agreement. The kappa statistic is commonly interpreted as follows: 0.21-0.40 indicates fair agreement, $0.41-0.60$ indicates moderate agreement, and 0.61-0.80 indicates substantial agreement (Landis and Koch, 1977). The positive percent agreement (PPA) represents the proportion of men citing a cause at both attempts over the total proportion of men citing that cause at either attempt. Finally, select quotations from narrative accounts of a dozen different respondents are included to supplement the aforementioned analyses and inform the discussion.

\section{RESULTS}

Detailed sample characteristics can be seen elsewhere (Wang et al., 2013), but briefly, the gay men in this sample have an average age of 37.2 years (standard deviation 12 years), 47\% have completed tertiary schooling, $45 \%$ live in a place with at least 100,000 inhabitants, and $59 \%$ are currently single.

\section{Suicidality}

The lifetime and 12-month percentages of suicidal ideation, suicide plans, and suicide attempts are shown in Table 1. Half the men $(52.3 \%)$ reported one or more of the three forms of suicidality in their lifetime and $19.3 \%$ in the past 12 months. Overall, $16.7 \%$ of the respondents reported one or more suicide attempts in their lifetime. 
TABLE 1. Lifetime and 12-Month Prevalence of Suicidality Among Gay Men in GGMHS, 2007 and $2011(N=762)$

\begin{tabular}{lcc}
\hline & Lifetime \% & $<\mathbf{1 2} \mathbf{~ m o} \%$ \\
\hline Any form of suicidality & 52.3 & 19.3 \\
Suicidal ideation & 51.7 & 18.3 \\
Suicide plans & 31.6 & 9.2 \\
Suicide attempts & 16.7 & 2.0 \\
\hline
\end{tabular}

Among them, $40.5 \%$ reported one attempt, $24.1 \%$ two attempts, and $35.4 \%$ three or more attempts. The median age at first attempt is 17.5 years.

Among men who reported a suicide attempt in their lifetime (16.7\%), 88\% also reported a history of depression and $60.7 \%$ anxiety. Among men who reported a suicide attempt in the past 12 months $(2.0 \%), 57.1 \%(8 / 14)$ self-reported depression, and $71.4 \%(10 / 14)$ fulfilled clinical criteria for major depression in the same period.

Table 2 presents findings on the severity of the latest suicide attempt. Half the attempters (51.3\%) needed medical help after their suicide attempt. A third of the attempters $(32.8 \%)$ had clear intention to die, and an additional $37.9 \%$ had some intention to die.

\section{Perceived Causes of the Latest Suicide Attempt}

The causes reported by men for their latest suicide attempt are listed in Table 3. The most common causes cited were problems with love/relationship (19\%), accepting one's homosexuality (15.5\%), and depression $(11.2 \%)$. Problems with love/relationship consisted mostly of break-ups. Problems accepting one's homosexuality may be exemplified by the following statements: "discovery of my homosexuality and not being able to come to terms with it" or "the impossibility of imagining my life as a gay man". Only $2.6 \%$ of the respondents were not able name a cause. The most prominent categories are social/inter-personal problems (47.4\%), followed by (general) problems $(26.7 \%)$ and mental problems $(23.3 \%)$.

Problems with family, accepting one's homosexuality, malaise, and cumulation of things tend to be associated with stronger intent to die, although none reaches statistical significance. Cry for help $(\mathrm{OR}=0.07)$ is strongly and significantly associated with weak intent to die. As a category, problems with homosexuality $(\mathrm{OR}=4.25)$ is the only category significantly associated with stronger intent to die. In the categories (general) problems and social/inter-personal problems, some of the constituent individual causes tend to be associated with stronger intent whereas others tend to be associated with weaker intent.

In contrast, the odds ratios for medical severity are generally much closer to parity, and none of the causes nor categories is significantly associated with requiring medical help after a suicide attempt. However, the entire range can be found in the social/inter-personal

TABLE 2. Severity of Latest Suicide Attempt Among Gay Men Ever Attempting Suicide in Their Lifetime in GGMHS, 2007 and 2011 $(n=116)$

\begin{tabular}{lc}
\hline & $\mathbf{\%}$ \\
\hline Medical help needed & 51.3 \\
Intention to die & \\
Yes, absolutely & 32.8 \\
Yes, somewhat & 37.9 \\
No, not really & 19.8 \\
No, not at all & 9.5 \\
\hline
\end{tabular}

TABLE 3. Perceived Causes of the Latest Suicide Attempt and Their Impact on the Intent to Die and the Attempt's Severity Among Gay Men Ever Attempting Suicide in Their Lifetime, in GGMHS, 2007 and 2011

\begin{tabular}{|c|c|c|c|c|c|c|}
\hline & \multirow{2}{*}{\multicolumn{2}{|c|}{$\begin{array}{c}\begin{array}{c}\text { Latest } \\
\text { Attempt }\end{array} \\
(n=116)\end{array}$}} & \multirow{2}{*}{\multicolumn{2}{|c|}{$\begin{array}{c}\text { Intent to Die } \\
(n=82)\end{array}$}} & \multirow{2}{*}{\multicolumn{2}{|c|}{$\begin{array}{c}\begin{array}{c}\text { Medical Help } \\
\text { Needed }\end{array} \\
(n=60)\end{array}$}} \\
\hline & & & & & & \\
\hline & $n$ & $\%$ & OR & $95 \%$ CI & OR & $95 \%$ CI \\
\hline Disease (unspecified) & 3 & 2.6 & 0.84 & $(0.07-9.53)$ & NA & \\
\hline Mental disorder & 14 & 12.1 & 0.73 & $(0.22-2.35)$ & 1.33 & $(0.43-4.12)$ \\
\hline Depression & 13 & 11.2 & 0.64 & $(0.19-2.11)$ & 1.14 & $(0.36-3.64)$ \\
\hline Somatic disease & 0 & 0 & 0 & & 0 & \\
\hline Problems (general) & 31 & 26.7 & 0.46 & $(0.19-1.10)$ & 0.73 & $(0.32-1.67)$ \\
\hline $\begin{array}{c}\text { Cumulation of things/ } \\
\text { overwhelmed }\end{array}$ & 7 & 6.0 & 2.64 & $(0.31-22.8)$ & 0.71 & $(0.15-3.32)$ \\
\hline Cry for help/attention & 6 & 5.2 & $0.07 * *$ & $(0.01-0.65)$ & 0.96 & $(0.19-4.99)$ \\
\hline Mental problems & 27 & 23.3 & 1.27 & $(0.48-2.25)$ & 1.05 & $(0.45-2.49)$ \\
\hline Malaise & 7 & 6.0 & 2.64 & $(0.31-22.8)$ & 0.71 & $(0.15-3.32)$ \\
\hline Despair/fed up & 10 & 8.6 & 0.98 & $(0.24-4.03)$ & 0.96 & $(0.26-3.52)$ \\
\hline $\begin{array}{l}\text { Social/inter-personal } \\
\text { problems }\end{array}$ & 55 & 47.4 & 0.88 & $(0.40-1.97)$ & 0.76 & $(0.37-1.58)$ \\
\hline Violence & 5 & 4.3 & 0.62 & $(0.10-3.86)$ & 0.63 & $(0.10-3.93)$ \\
\hline Acceptance by others & 11 & 9.5 & 2.00 & $(0.41-9.79)$ & 0.33 & $(0.08-1.31)$ \\
\hline Social circle & 5 & 4.3 & 0.40 & $(0.08-2.08)$ & 0.96 & $(0.19-4.99)$ \\
\hline Loneliness & 8 & 6.9 & 1.28 & $(0.25-6.69)$ & 0.96 & $(0.23-4.05)$ \\
\hline Love/relationship & 22 & 19.0 & 0.41 & $(0.16-1.09)$ & 1.20 & $(0.47-3.05)$ \\
\hline Family & 10 & 8.6 & 4.21 & $(0.50-33.9)$ & 1.50 & $(0.40-5.62)$ \\
\hline Lifestyle problems & 2 & 1.7 & 0.41 & $(0.03-6.79)$ & NA & \\
\hline $\begin{array}{l}\text { Problems with } \\
\text { homosexuality }\end{array}$ & 19 & 16.4 & $4.25^{*}$ & $(0.93-19.5)$ & 1.09 & $(0.41-2.91)$ \\
\hline $\begin{array}{l}\text { Accepting one's } \\
\text { homosexuality }\end{array}$ & 18 & 15.5 & 3.94 & $(0.85-18.2)$ & 0.96 & $(0.35-2.62)$ \\
\hline Being different & 1 & 0.9 & NA & & NA & \\
\hline Don't know & 3 & 2.6 & 0.84 & $(0.73-9.53)$ & 0.47 & $(0.04-5.38)$ \\
\hline
\end{tabular}

${ }^{*} p<0.05,{ }^{* *} p<0.01$

NB: select spontaneous responses to open question coded and grouped into categories.

$\mathrm{NA}=$ not available because one of the squares has 0.

problems category, from problems with acceptance by others $(\mathrm{OR}=0.33)$ to family $(\mathrm{OR}=1.50)$.

\section{Perceived Causes of the First Suicide Attempt}

The causes reported by men for all initial attempts are listed in Table 4. Problems with love/relationship (18.1\%), accepting one's homosexuality $(16.4 \%)$, and family $(15.5 \%)$ were the most common causes reported. Problems with family were sometimes explicitly linked to the respondent's homosexuality: "my family's lack of understanding for my homosexuality and their complete rejection" or "my parents don't accept my homosexuality and disown me." The category social/ inter-personal problems accounts for over half of all initial suicide attempts $(55.2 \%)$, followed by mental problems $(20.7 \%)$ and problems with homosexuality $(19.0 \%)$.

Malaise and loneliness are most strongly associated with any repeat attempt, although neither reaches statistical significance. Problems with acceptance by others $(\mathrm{OR}=0.10)$ - e.g., "being different and rejected by others" - are least likely to be associated with any repeat attempt. The category social/inter-personal problems $(\mathrm{OR}=0.46)$ is less likely to be associated with any repeat attempt, but as is the case in 
TABLE 4. Perceived Causes of the First Attempt and Their Impact on Any Repeat Attempt Among Gay Men Ever Attempting Suicide in Their Lifetime, in GGMHS, 2007 and 2011

\begin{tabular}{|c|c|c|c|c|}
\hline & \multirow{2}{*}{\multicolumn{2}{|c|}{$\begin{array}{c}\text { First } \\
\text { Attempt }\end{array}$}} & \multirow{2}{*}{\multicolumn{2}{|c|}{$\begin{array}{c}\begin{array}{c}\text { Any Repeat } \\
\text { Attempt }\end{array} \\
(n=69)\end{array}$}} \\
\hline & & & & \\
\hline & $n$ & $\%$ & OR & $95 \% \mathrm{CI}$ \\
\hline Disease (unspecified) & 3 & 0.4 & 1.39 & $(0.12-15.8)$ \\
\hline Mental disorder & 16 & 13.8 & 1.62 & $(0.52-5.02)$ \\
\hline Depression & 12 & 10.3 & 0.96 & $(0.29-3.24)$ \\
\hline Somatic disease & 0 & 0 & - & - \\
\hline Problems (general) & 17 & 14.7 & 0.43 & $(0.15-1.21)$ \\
\hline $\begin{array}{l}\text { Cumulation of things/ } \\
\text { overwhelmed }\end{array}$ & 4 & 3.4 & 0.22 & $(0.02-2.17)$ \\
\hline Cry for help/attention & 4 & 3.4 & 0.22 & $(0.02-2.17)$ \\
\hline Mental problems & 24 & 20.7 & 1.10 & $(0.43-2.79)$ \\
\hline Malaise & 5 & 4.3 & 2.12 & $(0.21-21.1)$ \\
\hline Despair/fed up & 4 & 3.4 & 0.22 & $(0.02-2.17)$ \\
\hline Social/inter-personal problems & 64 & 55.2 & $0.46^{*}$ & $(0.21-0.99)$ \\
\hline Violence & 6 & 5.2 & 1.41 & $(0.25-8.01)$ \\
\hline Acceptance by others & 7 & 6.0 & $0.10^{*}$ & $(0.01-0.88)$ \\
\hline Social circle & 5 & 4.3 & 0.44 & $(0.07-2.77)$ \\
\hline Loneliness & 11 & 9.5 & 1.96 & $(0.49-7.80)$ \\
\hline Love/relationship & 21 & 18.1 & 0.45 & $(0.17-1.16)$ \\
\hline Family & 18 & 15.5 & 1.46 & $(0.51-4.23)$ \\
\hline Lifestyle problems & 5 & 4.3 & 1.75 & $(0.79-1.75)$ \\
\hline Problems with homosexuality & 22 & 19.0 & 1.15 & $(0.44-3.05)$ \\
\hline $\begin{array}{l}\text { Accepting one's } \\
\text { homosexuality }\end{array}$ & 19 & 16.4 & 0.84 & $(0.31-2.32)$ \\
\hline Being different & 5 & 4.3 & 1.75 & $(0.79-1.75)$ \\
\hline Don’t know & 5 & 4.3 & 1.75 & $(0.79-1.75)$ \\
\hline
\end{tabular}

${ }^{*} p<0.05$.

NB: select spontaneous responses to open question coded and grouped into categories.

several categories, some of the constituent causes tend to be associated with higher risk whereas others with lower.

\section{Perceived Causes in Multiple Attempts}

Table 5 compares the perceived causes of the first and the most recent subsequent suicide attempts among men with multiple attempts. Problems with family $(17.6 \%)$, accepting one's homosexuality (14.7\%), and love/relationship (13.2\%) were the most common causes reported by multiple attempters for the first suicide attempt. Problems with love/relationship (14.5\%) and accepting one's homosexuality (14.5\%) remained the most common causes reported for the most recent subsequent attempt.

Generally, problems with depression, violence, love/relationship, and accepting one's homosexuality are reported at nearly equal levels at both the first and the most recent subsequent suicide attempts (McNemar test statistic $p=1.00$ ). Most perceived causes and categories demonstrate significant kappa and substantial PPA, underscoring the likelihood of a perceived cause to precipitate not only the first attempt but also a subsequent attempt in the same person. Substantial proportions of those who reported depression $(\mathrm{PPA}=50 \%$, kappa $=0.63)$, problems accepting one's homosexuality $(\mathrm{PPA}=40 \%$, kappa $=0.50)$, and loneliness $(\mathrm{PPA}=30 \%$, kappa $=0.41)$ as causes for their most recent subsequent attempt also reported the very same cause at their initial attempt, with the kappa coefficients indicating a moderate or, in the case of depression, substantial agreement. Correspondingly, mental disorder $(\mathrm{PPA}=42.9 \%$, kappa $=0.53)$, social/inter-personal problems $(\mathrm{PPA}=42.5 \%$, kappa $=0.32)$, and problems with homosexuality $(\mathrm{PPA}=38.9 \%$, kappa $=0.46)$ are the categories with the highest positive percent agreement.

These findings also reveal some interesting changes between attempts. Problems with family (McNemar test statistic $p=0.04)$ and being different (McNemar test statistic $p=0.06$ ) account for a much lower proportion of the most recent subsequent suicide attempts, whereas despair (McNemar test statistic $p=0.03$ ) accounts for a much higher proportion. Although the category social/inter-personal problems remains the most prominent at both attempts, it accounts for one half (47.1\%) of first attempts but only a third (34.8\%) of most recent subsequent attempts (McNemar test statistic $p=0.09$ ). The (general) problems category accounts for three times as many of the most recent subsequent attempts (30.4\%) as it does initial attempts $(10.3 \%)$ (McNemar test statistic $p=0.003$ ), but it has the lowest positive percent agreement $(\mathrm{PPA}=16.7 \%$, $\mathrm{kappa}=0.16)$.

\section{Supplementary Findings From the Narratives}

Finally, the narrative accounts contain additional findings which are not apparent in the tables. Most men reported more than one cause, with some men mentioning explicitly a sense of being overwhelmed by multiple causes - e.g., "everything just piled up all at once" or "too many worries which seemed insurmountable at the time". An articulate narrative illustrates how multiple perceived causes in various categories at individual, inter-personal, and societal levels may interact: "A malaise due to the way others viewed my personality, as there was suspicion surrounding my homosexuality, and it was often spoken of in an aggressive, mocking manner. Since homosexuality was taboo at the time and I wasn't normal, this social context proved very difficult for my personal development." Finally, it is important to note that break-downs in communication-e.g., "the inability to talk with someone" or "not being able to speak of my suffering"-not only thwarted help-seeking and social support but were named as an exacerbating cause.

\section{DISCUSSION}

Using both quantitative and qualitative approaches (Weiss, 2001), this paper presents additional insights into suicide attempts among gay men via their perceived causes.

\section{Multitude of Perceived Causes}

Gay men with a previous suicide attempt reported a wide variety of causes, with most individuals reporting multiple causes and many of the most common causes reported at both the first and most recent subsequent attempts. Both multiplicity and great heterogeneity in perceived causes have been demonstrated in other cultural epidemiological studies of deliberate self-harm (Parkar et al., 2006) and suicide (Parkar et al., 2009, 2012). A multitude of causes is very likely a key feature of suicide attempts generally. Because it has now been shown to apply to sexual minorities, this could be one explanation why even the most common factors do not account for all the (excess) risk of suicide and suicidality among sexual minorities (Haas et al., 2011). The implication for research is that qualitative assessment of causes are likely to be more complete. The implication for prevention is that there is no magic bullet, and multiple and multi-faceted approaches are needed.

\section{Most Prominent Causes}

Problems with love/relationship and accepting one's homosexuality figure consistently among the three most commonly reported causes. Whereas the former tend to be associated with weakest intent to die, the latter are associated with the strongest intent to die and with 
TABLE 5. Degree of Concordance Between Perceived Causes of the First and the Most Recent Subsequent Suicide Attempt Among Gay Men With Multiple Suicide Attempts in Their Lifetime, in GGMHS, 2007 and 2011

\begin{tabular}{|c|c|c|c|c|c|c|c|}
\hline & \multirow{2}{*}{\multicolumn{2}{|c|}{$\begin{array}{c}\text { First Attempt } \\
(n=69) \\
\end{array}$}} & \multirow{2}{*}{\multicolumn{2}{|c|}{$\begin{array}{c}\text { Most Recent Subsequent Attempt } \\
(n=69) \\
\end{array}$}} & \multirow{3}{*}{$\begin{array}{c}\text { Positive } \\
\text { Agreement \% } \\
\end{array}$} & \multirow[b]{3}{*}{ McNemar Test } & \multirow[b]{3}{*}{ Kappa } \\
\hline & & & & & & & \\
\hline & $n$ & $\%$ & $n$ & $\%$ & & & \\
\hline Disease (unspecified) & 2 & 2.9 & 2 & 2.9 & 33.3 & 1.00 & $0.50 * * *$ \\
\hline Mental disorder & 11 & 16.2 & 9 & 13.0 & 42.9 & 0.73 & $0.53 * * *$ \\
\hline Depression & 7 & 10.3 & 8 & 11.6 & 50.0 & 1.00 & $0.63 * * *$ \\
\hline Somatic disease & 0 & 0 & 0 & 0 & - & - & - \\
\hline Problems (general) & 7 & 10.3 & 21 & 30.4 & 16.7 & 0.003 & 0.16 \\
\hline Cumulation of things/overwhelmed & 1 & 1.5 & 4 & 5.8 & 0.0 & 0.38 & -0.02 \\
\hline Cry for help/attention & 1 & 1.5 & 3 & 4.3 & 0.0 & 0.62 & -0.02 \\
\hline Mental problems & 14 & 20.6 & 18 & 26.1 & 26.9 & 0.65 & $0.25^{*}$ \\
\hline Malaise & 3 & 4.4 & 6 & 8.7 & 25.0 & 0.69 & $0.36^{* *}$ \\
\hline Despair/fed up & 1 & 1.5 & 7 & 10.1 & 14.3 & 0.03 & $0.23 * *$ \\
\hline Social/inter-personal problems & 32 & 47.1 & 24 & 34.8 & 42.5 & 0.09 & $0.32 * *$ \\
\hline Violence & 4 & 5.9 & 3 & 4.3 & 16.7 & 1.00 & $0.25^{*}$ \\
\hline Acceptance by others & 1 & 1.5 & 5 & 7.2 & 0.0 & 0.22 & -0.03 \\
\hline Social circle & 2 & 2.9 & 4 & 5.8 & 20.0 & 0.63 & $0.31 * *$ \\
\hline Loneliness & 8 & 11.8 & 5 & 7.2 & 30.0 & 0.45 & $0.41 * * *$ \\
\hline Love/relationship & 9 & 13.2 & 10 & 14.5 & 26.7 & 1.00 & $0.33 * *$ \\
\hline Family & 12 & 17.6 & 4 & 5.8 & 14.3 & 0.04 & 0.18 \\
\hline Lifestyle problems & 5 & 7.4 & 2 & 2.9 & 16.7 & 0.38 & $0.26^{*}$ \\
\hline Problems with homosexuality & 13 & 19.1 & 11 & 15.9 & 38.9 & 0.55 & $0.46^{* * *}$ \\
\hline Accepting one's homosexuality & 10 & 14.7 & 10 & 14.5 & 40.0 & 1.00 & $0.50^{* * *}$ \\
\hline Being different & 5 & 7.4 & 0 & 0 & 0.0 & 0.06 & 0.00 \\
\hline Don’t know & 5 & 7.4 & 3 & 4.3 & 14.3 & 0.69 & 0.21 \\
\hline
\end{tabular}

NB: select spontaneous responses to open question coded and grouped into categories.

${ }^{*} p<0.05,{ }^{* *} p<0.01, * * * p<0.001$.

multiple attempts. Problems with family are among the most common perceived causes at first attempt but not at the most recent subsequent attempt. Even so, they tend to be related to both the strongest intent to die and the greatest severity at last attempt.

Social/inter-personal problems constitute the most prominent category, cited in almost half of all first attempts. In cultural epidemiological studies of suicide in India (Parkar et al., 2009, 2012), social/ inter-personal problems also constituted the most prominent category, and problems with love/relationship and family were also among the most commonly reported causes. However, the advantage of the cultural epidemiological approach is perhaps best reflected in the stark differences between these findings and those from Mumbai which may reflect specificities in sampling (community $v s$. clinical), social group (sexual minorities vs. general population), and culture (Frenchspeaking Swiss vs. Marathi Indian).

Of note, the two most commonly reported causes are scarcely reflected in most mainstream and sexual minority studies of suicide, indicative of a gap between predominant methods of quantitative assessment of risk factors driven by experts and respondent-driven causes in qualitative assessments of risk. Although problems with love/ relationship and accepting one's homosexuality also featured prominently in other studies with qualitative assessments of causes among sexual minorities (Hutchison et al., 2003; Johnson et al., 2007), these issues have been largely ignored in suicide research among this population to date.

Only $10 \%$ of men attempting suicide cited depression as a cause. Though associated with weaker intent to die, it is the cause most likely to be reported at multiple attempts. Psychiatric disorders-especially depression - have been emphasized in the scientific literature as one of the strongest and most consistent risk factors for suicide and suicide attempts. Although a large majority of men who attempted suicide also self-reported and/or fulfilled clinical criteria for major depression in accordance with the mainstream literature, only $12.7 \%$ of men who reported both a lifetime suicide attempt and depression cited depression or any mental disorder as a cause for their suicide attempt. A larger proportion of such men $(23.5 \%)$ - but still a minority — mentioned a cause in the mental problems category.

One potential explanation is that depression in turn also has its causes, and using the same methodology, we found striking similarities between the perceived causes for suicide attempt and those reported by men fulfilling diagnostic criteria for major depression in the past 12 months in the same study population (Wang et al., 2014b). For major depression, social/inter-personal problems constituted the most important category at initial outset, with the same top three causes-i.e., problems with love/relationship, accepting one's homosexuality, and family - as reported for the initial suicide attempt. An important distinction, however, is that although most categories seem to gain prominence between onset and the latest episode, problems accepting one's homosexuality drop out of the top three and become much less common in recent episodes of major depression.

Although psychiatric and social/inter-personal problems are usually found in most types of studies, their prominence is often reversed: psychiatric disorders are most prominent in typical quantitative studies whereas social/inter-personal problems are most prominent in studies with qualitative assessment. Quantitative assessments of risk factors predominate in suicide research, although such endeavors have 
not proven to be sensitive to picking up certain social/inter-personal causes - e.g., relationship problems - or simply ignore them altogether. Even quantitative assessments using lists of stressful live events (Brugha et al., 1985; Paykel et al., 1975) tend to yield findings closer to those from qualitative assessments, lending considerable credence to the latter. Unfortunately, studies with qualitative assessments of causes among actual attempters are relatively rare in both mainstream and sexual minority suicide research. We were able to locate only a handful of such studies among sexual minorities (Hutchison et al., 2003; Johnson et al., 2007; Rich et al., 1986), and the more recent studies have only been published as gray literature despite their high quality and value.

Interest in the two perspectives - affected individuals and professionals - does not necessitate making one authoritative and the other less so. From an anthropological analysis, they each have validity as representing a point of view, which has value for those who hold that point of view. An appreciation of this perspectivism and alternative explanations may be useful to both parties.

\section{Causes Non-specific to Sexual Minorities}

A recent review of the scientific literature on suicide and sexual orientation recommended exploring stable relationships as a potential protective factor and the salience of homosexual developmental milestones in future research (Haas et al., 2011). But just as family and work are protective when going well but may turn into serious risk factors when they do not (Shiner et al., 2009), relationships should not be treated only as a protective factor, but their problems also as potential risk factors for suicide. Qualitative findings from focus groups with gay men in Geneva underscored the importance of this issue generally: love/relationship was rated the most important domain for quality of life, but coupled with the lowest level of satisfaction (Wang et al., 2001)

The failure to consider problems with love/relationship is particularly startling because mainstream suicide research assessing life events identifies inter-personal problems as the most common category, and within that category, separation/rejection as the most common cause for both completed suicides (Foster, 2011) and non-lethal suicide attempts among both adults (Brugha et al., 1985; Michel et al., 1994; Weyrauch et al., 2001) and adolescents (Beautrais et al., 1997). As seen several decades earlier among men in San Diego, California (Rich et al., 1986), a recent autopsy study from the Queensland Suicide Register also found relationship problems to be the most prominent precipitating factor in completed suicides among both LGBT and matched general population controls: not only was it present among a majority of LGBT (65.7\% vs. $33.3 \%)$, but nearly four times as likely to be present $(\mathrm{OR}=3.76,95 \%$ CI 1.66-8.54) (Skerrett et al., 2014). Clearly, this issue deserves much greater attention in suicide research among sexual minorities.

Problems with family members were also prominent, especially at first attempt as evidenced in suicide and suicidality among adolescents generally (Dieserud et al., 2010; Hawton et al., 1982; Michel et al., 1994). In fact, such inter-personal problems can be considered as both proximal risk factors and triggers for suicide attempt generally (Bagge et al., 2013), further underscoring their importance.

\section{Causes Specific to Sexual Minorities}

Although many prominent causes are common to both sexual minorities and the general population, problems accepting one's homosexuality constitute a category of causes specific to sexual minorities. Despite meaningful improvements in social acceptance in recent decades, this process of coming to terms with one's own homosexuality has remained challenging for new generations and offers one explanation as to the persistence of high levels of morbidity-including suicidality-found among sexual minority youth (Wang et al., 2012, 2014a).

In qualitative studies, nearly all narratives of how participants experienced homosexual milestones included difficult and even traumatic personal and inter-personal struggles (Johnson et al., 2007; Mayock et al., 2009). In fact, $60 \%$ of the respondents in one study attributed their depression symptoms and suicidality directly to personal and/or inter-personal problems around their sexual orientation (Mayock et al., 2009). It is vital to note, however, that same-sex attraction was experienced as "comfortable and positive" until respondents realized that such "feelings positioned them as 'gay" (Johnson et al., 2007) Clearly then, the root of suffering is the stigmatization of homosexuality, and indeed, the concept of stigma provides a thorough explanatory framework for the challenges faced by an individual in coming to terms with and accepting homosexuality at the societal, inter-personal, and intra-personal levels (Kaufman and Johnson, 2004).

In focus groups on general health and well-being in Geneva, gay men in all age groups spoke about self-acceptance, lending the clear impression that gay men of all ages - not just young gay men - may have on-going issues in their personal development with regards to their own homosexuality (Wang et al., 2001). In short, conceptual, narrative, and empirical accounts (Kaufman and Johnson, 2004; Mayock et al., 2009; Everett, 2015) all suggest that the very process of identity change/development poses serious challenges for each sexual minority person.

The higher prevalence and risk of suicidality among sexual minorities may be due to the presence of causes specific to sexual minorities as well as higher levels of exposure to non-specific causes shared with the general population. Indeed, there is empirical evidence for higher levels of exposure to all of the most prominent non-specific causes among sexual minorities.

\section{Perceived Causes not Specific to Suicide Attempt}

As evidenced in the suicide literature to date, many risk factors or causes are not specific to suicide. Similar findings for suicide attempt and major depression in this sample reflect those from a mixed-methods study among sexual minorities in Ireland which found similar causes across depression symptoms, suicidal ideation, selfharm, and suicide attempts (Mayock et al., 2009). As was the case for major depression in this sample (Wang et al., 2014b), Irish narratives also provided a clear picture of how causes at various levels may fit together: personal problems in coming to terms with one's sexual orientation (e.g., confusion and denial) were compounded by inter-personal problems (e.g., isolation and violence) due to societal norms (e.g., heterosexism and homophobia) (Mayock et al., 2009).

Social/inter-personal causes are most prominent for both suicide attempts and major depression among gay men. And yet terms such as discrimination and homophobia were mentioned explicitly by only a handful of men as causes for their own suicide attempt and depression, and their narratives placed discrimination at the macro societal level. When asked why gay men generally were more susceptible to depression than heterosexual men (Wang et al., 2014b), discrimination was the number one reason given. Indeed, discrimination and homophobia may be reflected in the social/inter-personal problems reported, although the terms themselves were not necessarily used to label those problems. This experience shows that different questions may be needed to better capture proximal and distal causes, especially those at the macro level.

\section{LIMITATIONS}

The mode of data collection in these surveys - self-completed computer-assisted interviews - differs from that of most surveys in cultural epidemiology and clinical studies of suicide attempts which rely on face-to-face interviews. Although there is no interviewer bias, spontaneous responses were collected for open questions without probes or rankings. Research using the EMIC has shown that the frequency of the 
response items can change dramatically after probing, although this varies from item to item (Jadhav et al., 2001; Parkar et al., 2008). However, spontaneous responses are weighted more heavily than responses to probes within the EMIC framework. The method also differs from suicide studies assessing life events which tend to use longer or shorter checklists (Brugha et al., 1985; Paykel et al., 1975). Consequently, the frequencies of spontaneous responses presented here should be understood as conservative estimates of the actual prominence of these items.

Coding verbatim responses produced rich item lists for each question, but only one third of the items were sufficiently common to be analyzed individually, with the remainder analyzed only at the category level. Items were only analyzed individually due to low numbers, even though most respondents cited multiple causes. In fact, the multiplicity of perceived causes should raise the issue of sample size in both qualitative and quantitative studies, as it is unclear when saturation of themes has been reached. Furthermore, categories need to be constructed and used with caution. Although conceptually meaningful, they may enhance relationships in some instances and obscure them in others-i.e., when individual causes within a single category relate differently to an outcome. Different schemes in coding and categorizing make cross-study comparisons tricky. Nevertheless, the responses to open questions extend beyond the usual selection of risk factors in quantitative research as well as checklists of life events, underscoring the value of this approach.

Although the number of suicide attempters is typical for both cultural epidemiological studies and psychological autopsies, statistical power may be insufficient to capture some differences. To our knowledge, this is the first study to demonstrate the impact of perceived causes on related phenomena such as intent to die, medical severity, and repeat attempts. Despite the limitation of low power, individual causes seem to have a different impact, with some causes associated with greater risk and others with lesser. Replication of these findings in a larger sample would be most welcome.

This study used time-space sampling which provides robust coverage of gay men living in urban areas (Pollack et al., 2005). As such, unlike most clinical and qualitative studies on this issue, these findings may be generalized to gay men in the reference population, but it is important to note that the sample does not include men who do not access the meeting points, such as men who are not yet socially active with other gay men or sexually active with other men.

\section{CONCLUSIONS}

These findings shine a spotlight on existing gaps and point to future directions for suicide research and prevention among sexual minorities. Nearly all gay men are able to name causes which precipitated their suicide attempt. Their reported causes provide a more complete picture of the sheer multitude of causes in suicide attempt than quantitative risk factors alone. Their import and validity are supported by the different impact of certain causes on severity and recidivism. The similarity in perceived causes between major depression and suicide attempt on the one hand yet shifts in some causes over time on the other point to the utility of life-course approaches in both care and research. The prominence of social/inter-personal causes in both suicide attempt and major depression challenges the myopic emphasis on psychiatric risk factors in suicide research.

The prominence of social/inter-personal problems and problems accepting one's homosexuality in both suicide attempt and major depression underscores the continued need for socio-political changes to mitigate the stigma of homosexuality, eradicating discrimination and homophobia at the meso and macro levels but also supporting individual personal development by bolstering inter-personal skills to cope with relationship issues and psychological processes in coming to terms with one's homosexuality. Research and prevention need to address prominent non-specific causes such as problems with love/ relationship which have been largely ignored to date in both the general population and sexual minorities. For sexual minorities, research and prevention also need to address group-specific problems with homosexuality. Rather than simply subsuming them under the mantle of discrimination and homophobia at the macro level, such activities also need to address difficulties at the personal and interpersonal levels where the problems are most perceptible to the affected persons.

\section{ACKNOWLEDGMENTS}

The authors thank Fabien Bertrand, recruitment coordinator for the 2011 survey, and Richard Zahno, recruitment coordinator for the 2007 survey, and their recruitment teams. Special acknowledgment goes to project leaders Guillaume Mandicourt and Sylvie Berrut who assisted the research team in addition to developing materials for the depression awareness campaign Blues-out.

\section{DISCLOSURES}

The Blues-out campaign was financed by grants from the canton of Geneva and the Swiss AIDS Foundation. The process and outcome evaluations were financed by an anonymous private grant to the University of Zurich.

The authors declare no conflict of interest.

\section{REFERENCES}

Bagge CL, Glenn CR, Lee H-J (2013) Quantifying the impact of recent negative life events on suicide attempts. J Abnorm Psychol. 122:359-368.

Beautrais AL, Joyce PR, Mulder RT (1997) Precipitating factors and life events in serious suicide attempts among youths aged 13 through 24 years. J Am Acad Child Adolesc Psychiatry. 36:1543-1551.

Brugha T, Bebbington P, Tennant C, Hurry J (1985) The List of Threatening Experiences: a subset of 12 life event categories with considerable long-term contextual threat. Psychol Med. 15:189-194.

Bucholz KK, Cadoret R, Cloninger CR, Dinwiddie SH, Hesselbrock VM, Nurnberger JI, Reich T, Schmidt I, Schuckit MA (1994) A new semi-structured psychiatric interview for use in genetic linkage studies: a report on the reliability of the SSAGA. J Stud Alcohol. 55:149-158.

Bursztein C, Apter A (2008) Adolescent suicide. Curr Opin Psychiatry. 22:1-6.

Cash SJ, Bridge JA (2009) Epidemiology of youth suicide and suicidal behavior. Curr Opin Pediatr. 21:613-619.

Cleary A (2012) Suicidal action, emotional expression, and the performance of masculinities. Soc Sci Med. 74:498-505.

Dieserud G, Gerhardsen RM, Van den Weghe H, Corbett K (2010) Adolescent suicide attempts in Bærum, Norway, 1984-2006: trends, triggers, and underlying reasons. Crisis. 31:255-264.

Eurostat (2007) European Health Interview Survey (EHIS) 1st Round 2007-2008. background and rationale of the questions. Brussels: European Commission.

Everett B (2015) Sexual orientation identity change and mental health: a longitudinal analysis. J Health Soc Behav. 56:37-58.

Foster T (2011) Adverse life events proximal to adult suicide: a synthesis of findings from psychological autopsy studies. Arch Suicide Res. 15:1-15.

Gvion Y, Apter A (2012) Suicide and suicidal behavior. Public Health Rev. 34:1-20.

Haas AP, Eliason M, Mays VM, Mathy RM, Cochran SD, D’Augelli AR, Silverman MM, Fisher PW, Hughes T, Rosario M, Russell ST, Malley E, Reed J, Litts DA, Haller E, Sell RL, Remafedi G, Bradford J, Beautrais AL, Brown GK, Diamond GM, Friedman MS, Garofalo R, Turner MS, Hollibaugh A, Clayton PJ (2011) Suicide and suicide risk in lesbian, gay, bisexual, and transgender populations: review and recommendations. J Homosex. 58:10-51.

Hawton K, O’Grady J, Osborn M, Cole D (1982) Adolescents who take overdoses: their characteristics, problems and contacts with helping agencies. Br J Psychiatry. 140:118-123.

Hjelmeland H, Knizek BL (2010) Why we need qualitative research in suicidology. Suicide Life Threat Behav. 40:74-80 
Hutchison C, Porter S, De Voil S (2003) Live to tell: finding of study of suicidal thoughts, feelings and behaviours amongst young gay and bisexual men in Edinburgh. Edinburgh: Gay Men's Health.

Jadhav S, Weiss MG, Littlewood R (2001) Cultural experience of depression among white Britons in London. Anthropol Med. 8:47-69.

Johnson K, Faulkner P, Jones H, Welsh E (2007) Understanding suicidal distress and promoting survival in lesbian, gay, bisexual and transgender (LGBT) communities. Brighton: University of Brighton.

Kaufman JM, Johnson C (2004) Stigmatized individuals and the process of identity. Socio Q. 45:807-833.

Kessler RC, Andrews G, Mroczek D, Üstün B, Wittchen H-U (1998) The World Health Organization Composite International Diagnostic Interview Short-Form (CIDI-SF). Int J Methods Psychiatr Res. 7:171-185.

King M, Semlyen J, Tai SS, Killaspy H, Osborn D, Popelyuk D, Nazareth I (2008) A systematic review of mental disorder, suicide, and deliberate self-harm in lesbian, gay and bisexual people. BMC Psychiatry. 8:70.

Kjøller M, Helweg-Larsen M (2000) Suicidal ideation and suicide attempts among adult Danes. Scand J Public Health. 28:54-61.

Landis JR, Koch GG (1977) The measurement of observer agreement for categorical data. Biometrics. 33:159-174.

MacKellar D, Valleroy L, Karon J, Lemp G, Janssen R (1996) The Young Men's Survey: methods for estimating HIV prevalence and risk factors among young men who have sex with men. Public Health Rep. 111(suppl): $138-144$.

Mayock P, Bryan A, Carr N, Kitching K (2009) Supporting LGBT lives: a study of the mental health and well-being of lesbian, gay, bisexual and transgender people. Dublin: National Office of Suicide Prevention. Dublin: Gay and Lesbian Equality Network and BeLonG To Youth Service.

Michel K, Valach L, Waeber V (1994) Understanding deliberate self-harm: the patients' views. Crisis. 15:172-178.

Nock MK, Borges G, Bromet EJ, Cha CB, Kessler RC, Lee S (2008) Suicide and suicide behavior. Epidemiol Rev. 30:133-154.

Nosikov A, Gudex C (2003) EUROHIS: Developing Common Instruments for Health Surveys. Amsterdam: IOS Press.

Parkar SR, Dawani V, Weiss MG (2006) Clinical diagnostic and sociocultural dimensions of deliberate self-harm in Mumbai, India. Suicide Life Threat Behav. $36: 223-238$

Parkar SR, Dawani V, Weiss MG (2008) Gender, suicide, and the sociocultural context of deliberate self-harm in an urban general hospital in Mumbai, India. Cult Med Psychiatry. 32:492-515.

Parkar SR, Nagarsekar BB, Weiss MG (2009) Explaining suicide in an urban slum of Mumbai, India: a sociocultural autopsy. Crisis. 30:192-201.

Parkar SR, Nagarsekar BB, Weiss MG (2012) Explaining suicide: identifying common themes and diverse perspectives in an urban Mumbai slum. Soc Sci Med. 75:2037-2046

Paykel ES, Myers JK, Lindenthal JJ, Tanner J (1974) Suicidal feelings in the general population: a prevalence study. Br J Psychiatry. 124:460-469.

Paykel ES, Prusoff BA, Myers JK (1975) Suicide attempts and recent life attempts. Arch Gen Psychiatry. 32:327-333.
Plöderl M, Sauer J, Fartacek R (2006) Suizidalität und psychische Gesundheit von homo- und bisexuellen Männern und Frauen - eine Metaanalyse internationaler Zufallsstichproben. Verhaltenstherapie \& psychosoziale Praxis. 38:283-302.

Plöderl M, Wagenmakers E-J, Tremblay P, Ramsay R, Kralovec K, Fartacek C, Fartacek R (2013) Suicide risk and sexual orientation: a critical review. Arch Sex Behav. 42:715-727.

Pollack LM, Osmond DH, Paul JP, Catania JA (2005) Evaluation of the Center for Disease Control and Prevention's HIV Behavioral Surveillance for men who have sex with men: sampling issues. Sex Transm Dis. 32:581-589.

Rich CL, Fowler RC, Young D, Blenkush M (1986) San Diego Suicide Study: comparison of gay to straight males. Suicide Life Threat Behav. 16:448-457.

Sauerborn C, Banerjee S (2006) Striking contrasts: cultural dimensions of suicidal behaviour in the Sundarban region, India, and Basel, Switzerland. Medicus Mundi Schweiz Bulletin. 100:10-13.

Scourfield J, Fincham B, Langer S, Shiner M (2012) Sociological autopsy: an integrated approach to the study of suicide in men. Soc Sci Med. 74:466-473.

Shiner M, Scourfield J, Fincham B, Langer S (2009) When things fall apart: gender and suicide across the life-course. Soc Sci Med. 69:738-746.

Skerrett DM, Kõlves K, De Leo D (2014) Suicides among lesbian, gay, bisexual, and transgender populations in Australia: an analysis of the Queensland Suicide Register. Asia Pac Psychiatry. 6:440-446.

Skogman Pavulans K, Bolmsjö I, Edberg AK, Öjehagen A (2012) Being in want of control: experiences of being on the road to, and making, a suicide attempt. Int J Qual Stud Health Well-being. 7:16228.

Stueve A, O'Donnell LN, Duran R, San Doval A, Blome J (2001) Time-space sampling in minority communities: results with young Latino men who have sex with men. Am J Public Health. 91:922-926.

Valach L, Michel K, Young RA, Dey P (2006) Suicide attempts as social goal-directed systems of joint careers, projects, and actions. Suicide Life Threat Behav. 36: $651-660$

Wang J, Dey M, Soldati L, Weiss MG, Gmel G, Mohler-Kuo M (2014a) Psychiatric disorders, suicidality, and personality among young men by sexual orientation. Eur Psychiatry. 29:514-522

Wang J, Häusermann M, Berrut S, Weiss MG (2013) The impact of a depression awareness campaign on mental health literacy and mental morbidity among gay men. J Affect Disord. 150:306-312.

Wang J, Häusermann M, Rias A (2001) Santé gaie Project: first-round focus group discussions among gay men in Geneva on health, needs, and strategies. Geneva: Dialogai.

Wang J, Häusermann M, Weiss MG (2014b) Mental health literacy and the experience of depression in a community sample of gay men. J Affect Disord. 155: 200-207.

Wang J, Häusermann M, Wydler H, Mohler-Kuo M, Weiss MG (2012) Suicidality and sexual orientation among men in Switzerland: findings from 3 probability surveys. J Psychiatr Res. 46:980-986.

Weiss M (1997) Explanatory Model Interview Catalogue (EMIC): framework for the comparative study of illness. Transcult Psychiatry. 34:235-263.

Weiss M (2001) Cultural epidemiology: an introduction and overview. Anthropol Med. 8:5-29.

Weyrauch KF, Roy-Byrne P, Katon W, Wilson L (2001) Stressful life events and impulsiveness in failed suicide. Suicide Life Threat Behav. 31:311-319. 